\title{
In Reply: Dominance of Ossicular Route in Sound Transmission
}

\author{
Hanaro Park · Seung No Hong $\cdot$ Hyo Sang Kim $\cdot$ Jae Joon Han $\cdot$ Juyong Chung $\cdot$ Myung-Whan Seo $\cdot$ Seung-Ha Oh \\ Sun-O Chang $\cdot$ Jun Ho Lee \\ Department of Otorhinolaryngology-Head and Neck Surgery, Seoul National University College of Medicine, Seoul, Korea
}

We reported that the degree of conductive hearing loss resulting from a tympanic membrane (TM) perforation would be expected with the size of perforation and pneumatization of middle ear and mastoid, not location of perforation. This result was conflicted with previous study that revealed the influence of location of TM perforation on the severity of hearing loss in 1970 [1].

When the perforation size was relatively large, the sound transmission via acoustic route would became dominant and airbone gap would increase more by phase cancelation at round window in posterior TM perforation rather than in anterior TM perforation $[2,3]$. Unfortunately, most of patients who were included in our study had small perforation size within $30 \%$ of $\mathrm{TM}(\mathrm{n}=34 / 44,77 \%)$. The authors agree with your comments which we did not mention in the discussion.

\section{CONFLICT OF INTEREST}

No potential conflict of interest relevant to this article was reported.

\section{REFERENCES}

1. Anthony WP, Harrison CW.Tympanic membrane perforation: effect on audiogram. Arch Otolaryngol. 1972 Jun;95(6):506-10.

2. Voss SE, Rosowski JJ, Merchant SN, Peake WT. How do tympanicmembrane perforations affect human middle-ear sound transmission? Acta Otolaryngol. 2001 Jan;121(2):169-73.

3. Voss SE, Rosowski JJ, Merchant SN, Peake WT. Non-ossicular signal transmission in human middle ears: experimental assessment of the "acoustic route" with perforated tympanic membranes. J Acoust Soc Am. 2007 Oct;122(4):2135-53.

\footnotetext{
- Received July 23, 2016

Accepted July 24, 2016

- Corresponding author: Jun Ho Lee

Department of Otorhinolaryngology-Head and Neck Surgery, Seoul

National University Hospital, Seoul National University College of

Medicine, 101 Daehak-ro, Jongno-gu, Seoul 03080, Korea

Tel: +82-2-2072-2448, Fax: +82-2-745-2387

E-mail: junlee@snu.ac.kr
}

Copyright $\odot 2016$ by Korean Society of Otorhinolaryngology-Head and Neck Surgery.

This is an open-access article distributed under the terms of the Creative Commons Attribution Non-Commercial License (http://creativecommons.org/licenses/by-nc/4.0)

which permits unrestricted non-commercial use, distribution, and reproduction in any medium, provided the original work is properly cited. 